Weixuan Jiao

Li Cheng $\square$

Di Zhang

Bowen Zhang

Yeping Su

https://doi.org/10.21278/TOF.451004819

ISSN 1333-1124

eISSN 1849-1391

\title{
INVESTIGATION OF KEY PARAMETERS FOR HYDRAULIC OPTIMIZATION OF AN INLET DUCT BASED ON A WHOLE WATERJET PROPULSION PUMP SYSTEM
}

\begin{abstract}
Summary
The hydraulic performance of an inlet duct directly affects the overall performance of a waterjet propulsion system. Key parameters for the hydraulic optimization of the inlet duct are explored using the computational fluid dynamics (CFD) technology to improve the hydraulic performance of the waterjet propulsion system. In the CFD simulation and experiment, an inlet duct with different flow and geometric parameters is simulated. By comparing grid sensitivity and different turbulence models, a suitable grid size and a turbulence model are determined. The comparison between the numerical simulation and the experiment shows that the numerical results are reliable. The results of the calculation and analysis of different speed cases show that the ship speed affects the efficiency of the waterjet propulsion system. In particular, the system efficiency increases first and then decreases with an increase in the ship speed. Under the conditions of constant ship speed and rotational speed, the influence of the length and dip angle of the inlet duct on the waterjet propulsion system is investigated using a single factor method. The results show that the dip angle has an obvious effect on the hydraulic performance of the inlet duct, and an extremely small angle of inclination will lead to poor flow patterns in the inlet passage. When the length is approximately six times the inlet duct outlet diameter, and the dip angle is $30^{\circ}-35^{\circ}$, the hydraulic performance of the waterjet propulsion pump system is satisfactory.
\end{abstract}

Key words: $\quad$ hydraulic performance; waterjet propulsion; inlet duct; optimization

\section{Introduction}

Waterjet propulsion is a special propulsion system different from a propeller. It has been extensively used in high-speed ships because of its high efficiency, low noise and vibration, and energy-saving advantages [1]. Given the increasing demand for waterjet propulsion systems in industrial production, military application and other innovations, waterjet-propelled ships are gradually developing from small- and medium-sized to largesized, efficient and high-speed ships [2-3]. A stern-mounted waterjet propulsion system is mainly composed of four parts: an inlet duct, a propulsion pump, a nozzle, and a steering 
device. All components need to play their roles to utilize the hydraulic performance of waterjet propulsion systems fully [4-5]. As a core component of the waterjet propulsion system, effective operation of the pump is conducive to the improvement of the overall system efficiency. Local and international experts and scholars conducted extensive research on the optimization of the pump, including centrifugal [6-7], mixed flow [8-9], and axial pumps [10-11]. With the improvement of design and manufacturing level of pumps, the operation stability and efficiency of mixed and axial flow pumps - being two commonly used pumps in waterjet propulsion systems - have been greatly enhanced [12-14]. Under the conditions of high cavitation speed, the excellent efficiency of mixed and axial flow pumps can reach up to $85 \%-90 \%$. Although the efficiency of propulsion pumps has been greatly improved, the market research results show that the propulsion efficiency of current waterjet propulsion systems remains low [15-16]. Scientists generally believed that the hydraulic performance of the inlet duct directly affects the uniformity of the flow field and the overall performance of the system, which is the main reason for the current low-level propulsion efficiency [17-18]. Previous studies [17, 19-20] showed that the power loss at the intake of the waterjet propulsion system accounts for $7 \%-9 \%$ of the total system power. The hydraulic loss of the inlet duct mainly includes the intake flow separation [21], constriction [22], blockage [23], and friction losses [24]. The hydraulic performance of the inlet duct affects the efficiency of the waterjet propulsion system and anti-cavitation, vibration and noise performance of the waterjet propulsion pump. To sum up, the hydraulic optimization of the inlet duct can further improve the overall performance of the waterjet propulsion system.

The computational fluid dynamics (CFD) numerical simulation technology is utilized to explore the influence of different flow and geometric parameters on the hydraulic performance of the inlet duct and the whole waterjet propulsion pump system and to find key parameters for the hydraulic optimization of the inlet duct. The model test is also used to verify the accuracy of the numerical simulation results. The research results can provide a valuable insight into optimal operation of the waterjet propulsion system and optimal design of the inlet duct.

\section{Numerical calculation}

CFD software is commonly used in the numerical simulation of the internal flow field of rotating machinery. Accordingly, the CFD software ANSYS ${ }^{\circledR}$ CFX 14.5 was used in this study to simulate the internal flow field of the waterjet propulsion system.

\subsection{Governing equations}

Reynolds-averaged $N-S$ and continuity equations were used to describe a 3D incompressible viscous flow as follows:

$$
\frac{\partial u_{i}}{\partial x_{i}}=0
$$

Then, a momentum conservation equation was applied as follows:

$$
\frac{\partial\left(\rho u_{i}\right)}{\partial t}+\frac{\partial\left(\rho u_{i} u_{j}\right)}{\partial x_{j}}=F_{i}-\frac{\partial p}{\partial x_{i}}+\frac{\partial}{\partial x_{j}}\left[\mu\left(\frac{\partial u_{i}}{\partial x_{j}}+\frac{\partial u_{j}}{\partial x_{i}}\right)\right],
$$

where $\rho$ represents water density $\left(\mathrm{kg} / \mathrm{m}^{3}\right) ; u_{i}, u_{j}$ represent velocity components of the fluid in the $i$ and $j$ directions $(\mathrm{m} / \mathrm{s}) ; t$ represents time $(\mathrm{s}) ; p$ represents pressure $(\mathrm{Pa}) ; F_{i}$ represents the volume force component in the $i$ direction $(\mathrm{N}) ; \mu$ represents dynamics viscosity $(\mathrm{Pa} \cdot \mathrm{s})$; and $x_{i}, x_{j}$ represent coordinate components. 


\subsection{Numerical model establishment}

The hull boundary layer, inflow velocity and pressure would affect the water flow. Thus, the water flow into the inlet duct was made non-uniform. A flow control volume (i.e., the water tank) should be defined to perform accurate numerical simulations of the waterjet propulsion system, as shown in Figure 1. The flow control volume would greatly affect the prediction accuracy of the performance of the waterjet propulsion system. Thus, the size of the water tank should be selected using a reasonable distribution of internal flow field parameters of the waterjet propulsion system. The length, width and depth of the water tank were $30 D_{0}, 10 D_{0}$, and $8 D_{0}$, respectively. Following Liu et al. [25], $D_{0}$ was used to denote the outlet diameter of the inlet duct. The whole computational domain was composed of a waterjet propulsion pump system and a water tank.

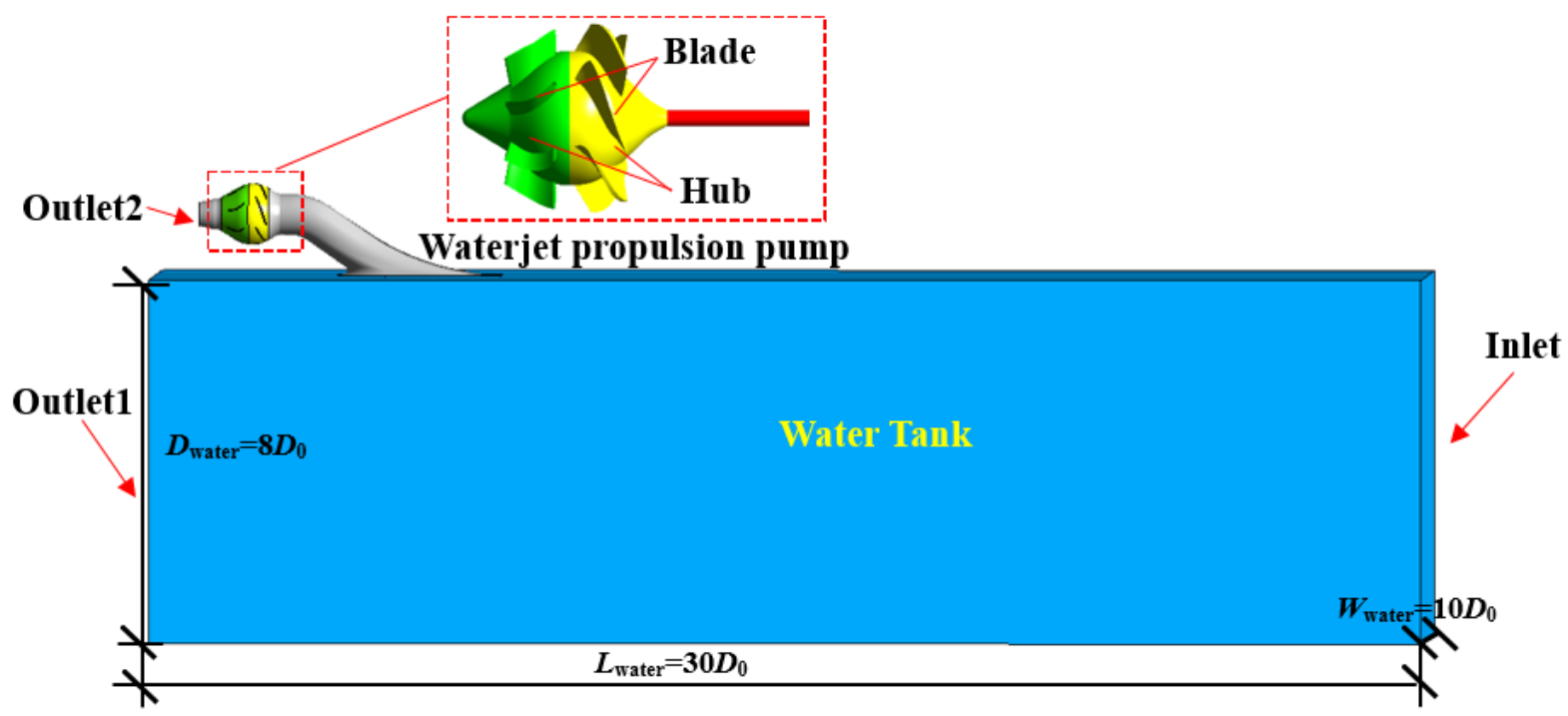

Fig. 1 Computational domain

The complete configuration of the waterjet propulsion pump system is depicted in Figure 2. As an important over-current component of the waterjet propulsion pump system, the main function of the nozzle is to transform the mechanical energy of the propulsion pump into the kinetic energy of the water and eject the water flow to obtain thrust. The outlet area of the nozzle was designed as 0.3 times larger than the outlet area of the inlet duct, and the outlet shape was made circular to improve the hydraulic performance of the nozzle. The geometric parameters of the nozzle were maintained in this study. The guide vane with seven blades was connected to the nozzle inlet. The impeller with six blades was connected to the guide vane inlet. The designed rotational speed $n_{d}$ was set at $700 \mathrm{r} / \mathrm{min}$. The hub and blade of the impeller were relatively static as well as the casing. The shape of the inlet duct was mainly affected by the lip structure, dip angle $\theta$, and the length $L$ of the inlet duct.

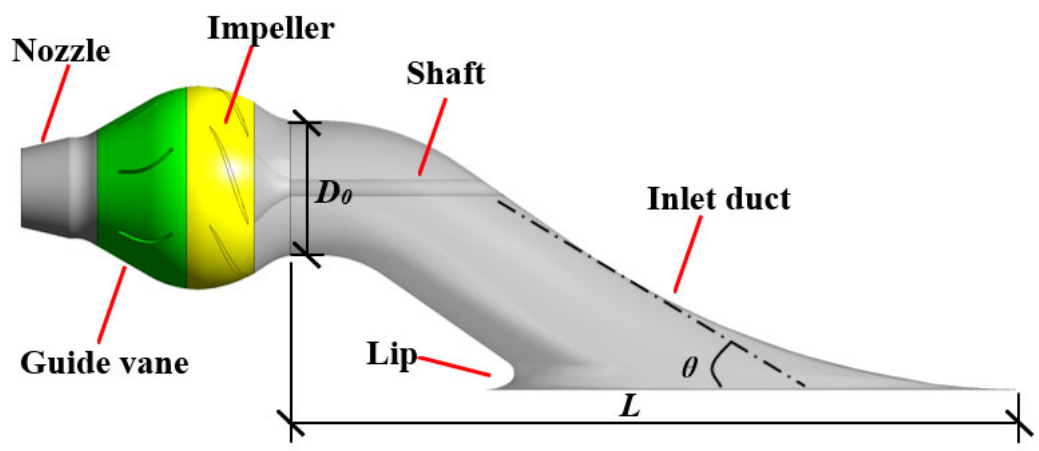

Fig. 2 Waterjet propulsion pump system 


\subsection{Grid size sensitivity analysis}

The grid of the computation domain is shown in Figure 3. The entire computational domain was generated with hexahedral elements. The grid of the inlet duct is presented in Figure 3(a). ICEM CFD software [26] was utilized to mesh the inlet duct, and the grid of local areas, such as the lip corner, was refined. When meshing the inlet duct, the minimum angle of the grid was maintained with a degree not less than $12^{\circ}$. The guide vane, impeller, and shaft of the propulsion pump were separately generated grids in ICEM CFD, as shown in Figure 3(b). The guide vane, the impeller and the clearance meshed periodically. The poor quality mesh was eliminated in this study through mesh refinement and Y-type mesh generation to ensure the grid quality of the propulsion pump.

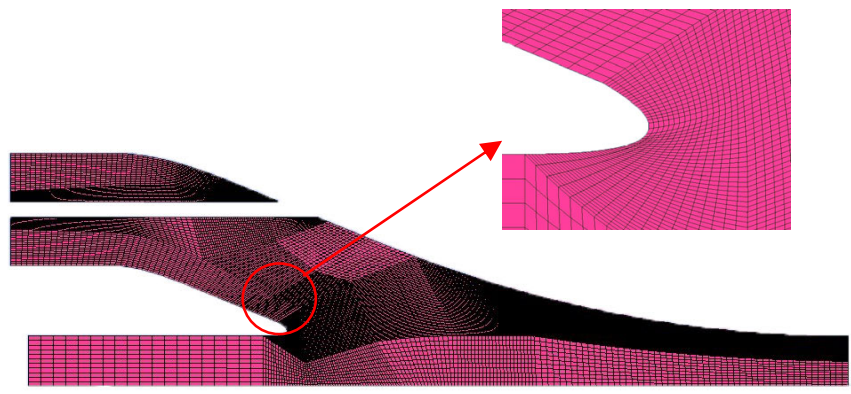

(a) Inlet duct

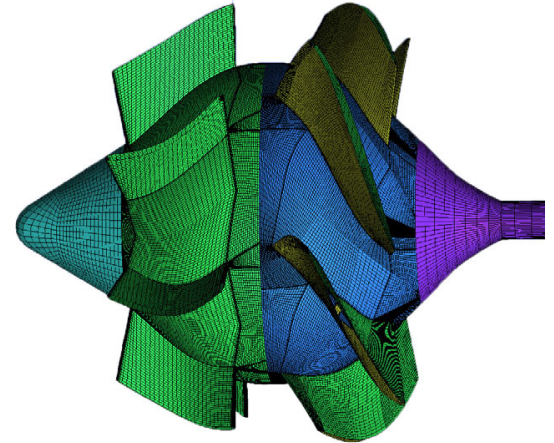

(b) Surface mesh of the propulsion pump

Fig. 3 Grid of the computational domain

As the grid number increases, the numerical results become closer to the exact solutions [27]. Further, as the grid number increases, the computational load and cycle also increase. The grid numbers could not be extremely large to maintain the accuracy of the solution. Therefore, the influence of the grid numbers on the calculation results was analysed in this study. Grid sensitivity was verified by changing the grid size. Hydraulic loss of the inlet duct was calculated while the grid was continuously refined until the calculation result tended to be stable. A total of 2,314,758, 2,454,108, 2,619,654, 2,752,791, and 2,853,183 cells of the inlet duct and water tank were used for numerical calculation. The number of cells of the computational domain is presented in Table $1 . \mathrm{Y}+$ is the dimensionless wall distance used to evaluate the grid quality of the first layer. Thus, while changing the grid density, the $y^{+}$ values were guaranteed to meet the computational requirements.

Table 1 Number of cells used in the computational domain

\begin{tabular}{cccccc}
\hline Case & $\mathrm{A}$ & $\mathrm{C}$ & $\mathrm{d}$ & $\mathrm{D}$ & $\mathrm{E}$ \\
\hline Inlet duct & $1,251,792$ & $1,391,142$ & $1,556,688$ & $1,689,825$ & $1,790,217$ \\
Water tank & $1,062,966$ & $1,062,966$ & $1,062,966$ & $1,062,966$ & $1,062,966$ \\
\hline
\end{tabular}

The hydraulic loss of the inlet duct changes as the grid number increases, as shown in Figure 4. $\Delta h$ represents the hydraulic loss of the inlet duct calculated using Eq. (4). In the grid size sensitivity analysis of the inlet duct, the following variables were used. The ship speed was set to $10 \mathrm{~m} / \mathrm{s}$, the inlet velocity ratio (IVR; the ratio of the ship speed to the averaged axial outflow velocity at the inlet duct outlet, $I V R=v_{s} / v_{p}$ ) was 1.0, and the residual target was controlled within $10^{-5}$. When the total number of cells of the inlet duct and water tank reached 2.62 million, the hydraulic loss was unchanged. The calculation results showed that when the total number of cells of the inlet duct and water tank exceeded 2,619,654, the 
hydraulic loss error was slightly changed, and the grid sensitivity met the calculation requirements. Therefore, the total number of cells of the whole computational domain containing the waterjet propulsion pump and nozzle was set to 6.09 million.

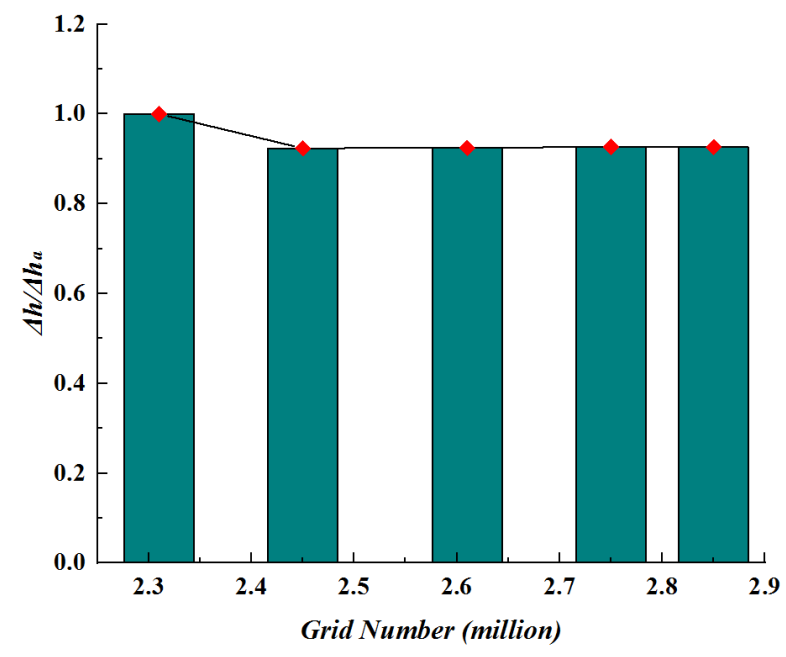

Fig. 4 Grid size sensitivity analysis

Note: $* \Delta h_{a}$ represents the hydraulic loss of the inlet duct in Case a.

\subsection{Turbulence model selection}

Numerous turbulence models can be used to solve different flow problems. However, the correct selection of the turbulence model in the numerical simulation is the premise to ensure the accuracy of the solution. $k-\varepsilon$ and $k-\omega$ were considered to be the most suitable for the calculation of the internal flow of rotating machines. The applicability of four turbulence models, i.e. standard $k-\varepsilon$, RNG $k-\varepsilon$, standard $k-\omega$ and SST $k-\omega$ in the performance calculation of the waterjet propulsion pump system was discussed and compared. Finally, an appropriate turbulence model for the performance calculation was determined. The comparison showed little difference between the calculated values. However, in the case of the standard $k-\varepsilon$ turbulence model, the calculated values were in good agreement with the experimental values. Therefore, the standard $k-\varepsilon$ was chosen as the calculation model in this study.

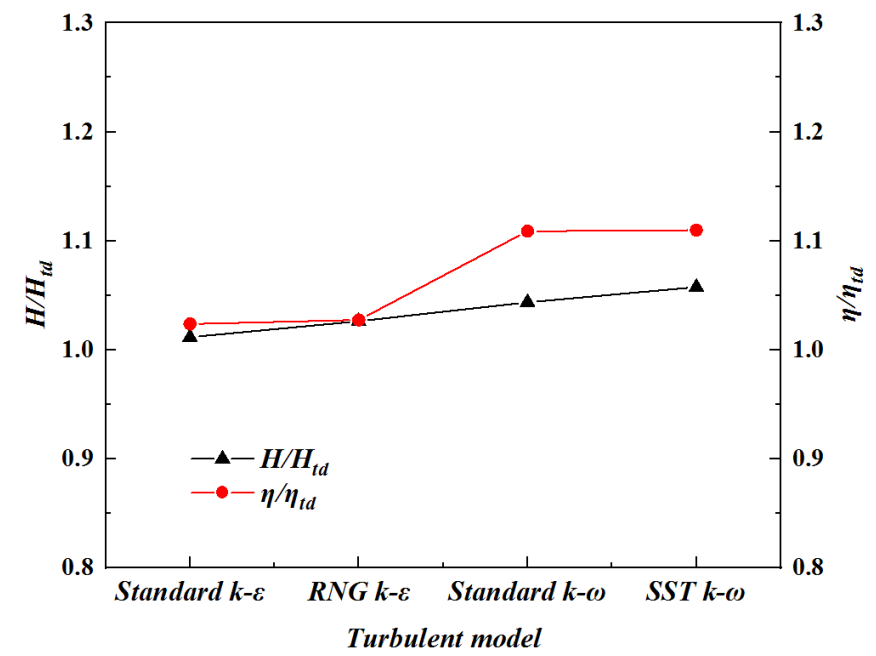

Fig. 5 Numerical and experimental results with different turbulence models

Note: ${ }^{*} H_{t d}$ represents the test value of head under design flow rate conditions, and $\eta_{t d}$ represents the test value of efficiency under design flow rate conditions. 


\subsection{Setting the boundary conditions}

The inlet of the water tank was set as the inlet boundary of the entire computational domain, and normal speed was adopted as the inlet boundary condition, as shown in Figure 2. In setting the velocity inlet boundary condition, the Wieghardt equation was used to simulate the actual inlet velocity due to the influence of the hull boundary layer. The inflow velocity was set equal to the ship speed, and nominal turbulence intensities (with values equivalent to $5 \%$ ) were used as the inlet boundary. The outlet of the water tank and the nozzle was set as the outlet boundary. The average static pressure outlet boundary condition was applied at the water tank outlet, and the mass-flow rate was adopted as the outlet boundary of the nozzle. No-slip wall condition was applied to all physical walls. The interface between the stationary and rotating frames was set as frozen stage condition. The convergence precision was set to $10^{-5}$.

\section{Hydraulic characteristic test}

\subsection{Test rig setup}

A test rig was built to study the hydraulic performance of the waterjet propulsion pump, as shown in Figure 6. The test rig was a closed circulation system composed of a main and a secondary circulation pipeline system. The main circulation pipeline system was designed to allow for the water circulation and provide bottom speed. The secondary circulation pipeline system was a circulating pipe used to test the performance of the waterjet propulsion pump system. The propulsion pumping system was composed of an impeller, a guide vane and an inlet duct, as shown in Figure 7. A propulsion pump with six impeller blades and a guide vane with seven stator vanes were built into the system. A scale model of a waterjet pump used for ship propulsion was provided. The head, flow rate, torque, and speed were tested to obtain the hydraulic performance of the waterjet propulsion pump. The pump was driven by a DC electric motor at speeds varying from $700 \mathrm{r} / \mathrm{min}$ to $2400 \mathrm{r} / \mathrm{min}$ and was equipped with an auxiliary axial pump to regulate the flow rate. The test rig had two electromagnetic flowmeters with an absolute accuracy of $\pm 0.5 \%$. These devices were used to test the flow rates of the main and the secondary circulation pipeline system. The head of the waterjet propulsion pump was measured using a differential pressure transmitter with an absolute accuracy of $\pm 0.2 \%$.

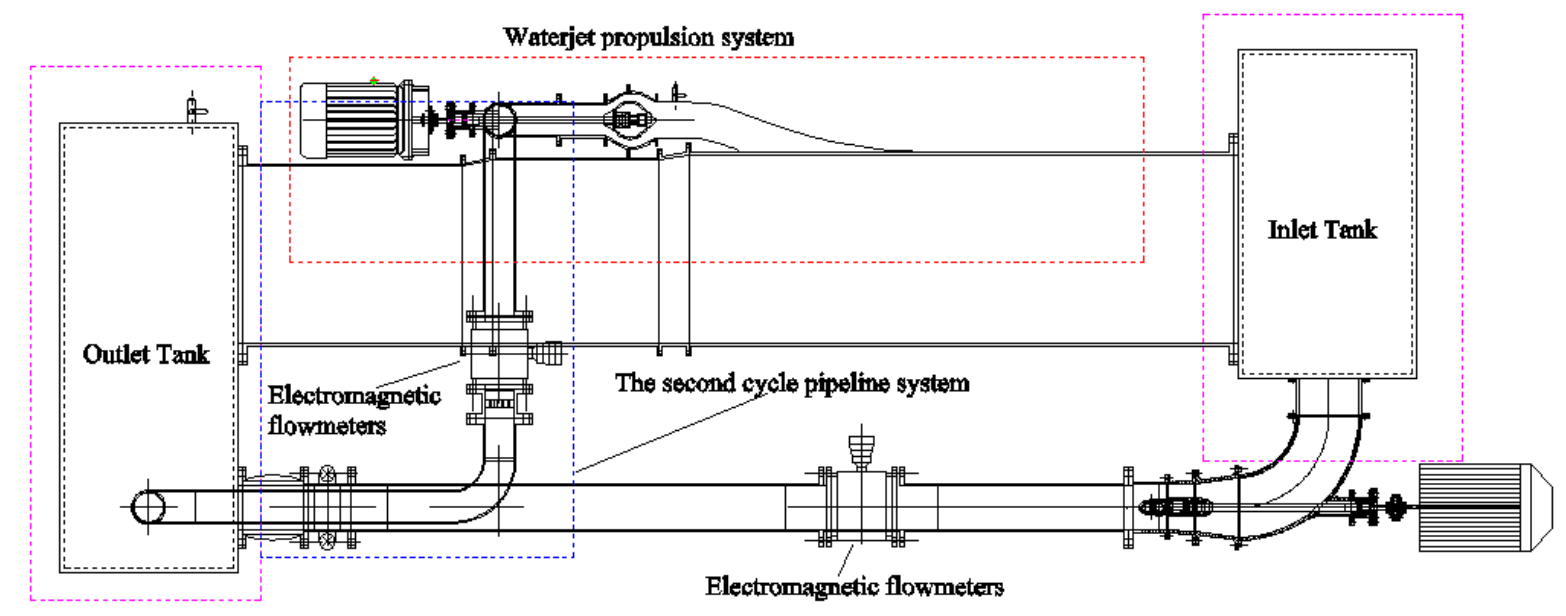

Fig. 6 Test rig setup 


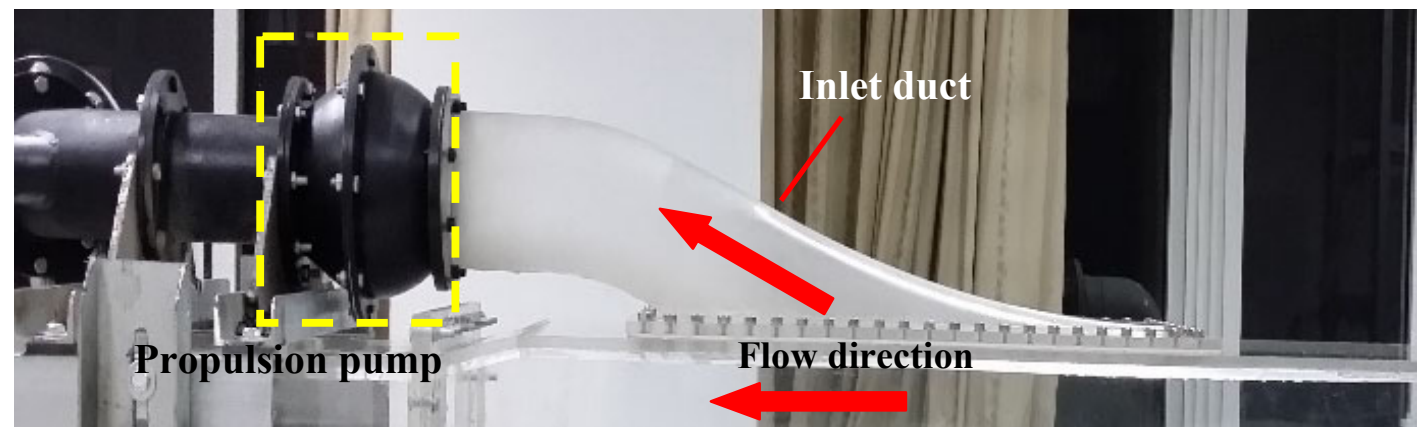

Fig. 7 Waterjet propulsion pumping system

\subsection{CFD and experiment verification}

In the numerical calculation, the front section (1-1) of the impeller inlet and the back section of the guide vane outlet (2-2) were taken as the pressure measuring section for the head calculation and analysis, as shown in Figure 8.

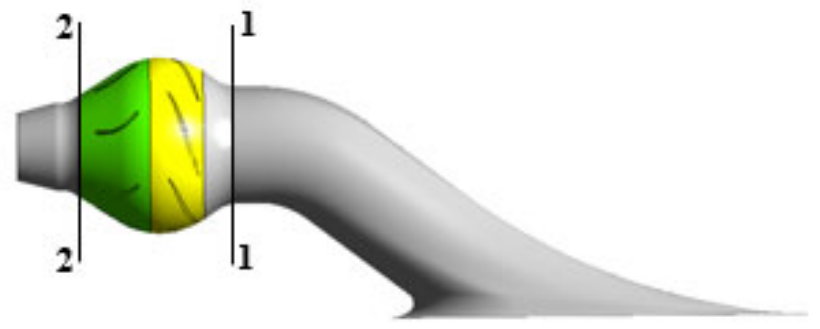

Fig. 8 Pressure measuring section

Pump efficiency $\eta$, shaft power $P$, and head $H$ are usually used to represent hydraulic characteristics of the waterjet propulsion pump system. Accordingly, the following formulas were used:

$$
\begin{aligned}
& p=p_{2-2}-p_{1-1}, \\
& H=\frac{p}{\rho g}, \\
& P=\frac{2 \pi T n}{1000 * 60}, \\
& \eta=\frac{\rho g Q H}{N},
\end{aligned}
$$

where $p$ is the pressure of section $(\mathrm{Pa}), p_{1-1}$ is the average total pressure of section 1-1 $(\mathrm{Pa})$, $p_{2-2}$ is the average total pressure of section 2-2 $(\mathrm{Pa}), g$ is the gravitational acceleration $\left(\mathrm{m} / \mathrm{s}^{2}\right)$, $T$ is the torque of blades $(\mathrm{N} \cdot \mathrm{m}), n$ is the rotational speed of the impeller $(\mathrm{r} / \mathrm{min})$, and $Q$ is the flow rate $\left(\mathrm{m}^{3} / \mathrm{s}\right)$.

The comparison between the calculation and the experimental results is shown in Figure 9. In general, the predicted $H$ and $\eta$ were in good agreement with the experimental results at different flow conditions. Under the design flow rate conditions, the numerical calculation results were closest to the test results. Under other flow rate conditions, due to the influence of flow separation and bad flow patterns in the propulsion pump, a certain deviation was observed between the calculation and the experimental results. However, this deviation was still within $3 \%$. Thus, the calculation results were reliable. 


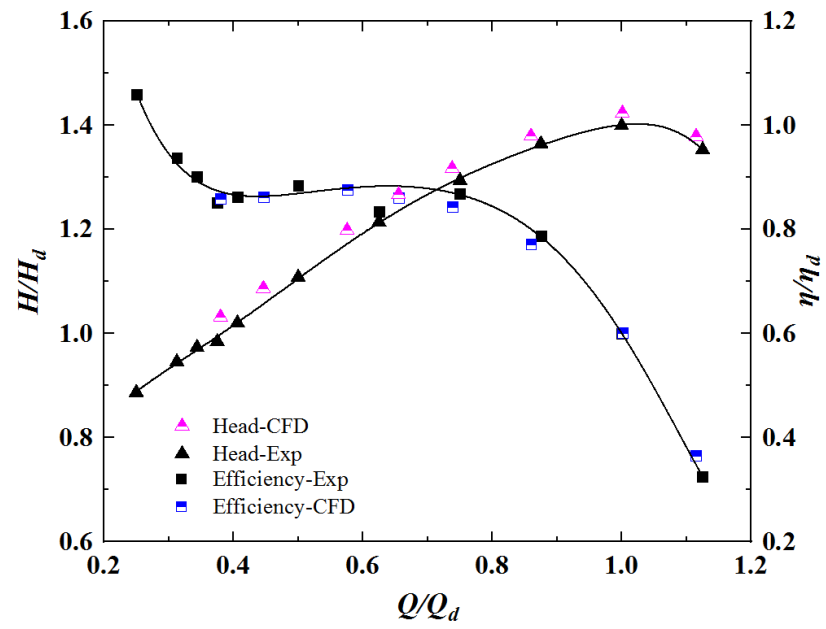

Fig. 9 Comparison between calculation and experimental results

Note: ${ }^{*} Q_{d}$ represents the design flow rate, and $H_{d}$ and $\eta_{d}$ represent the head and efficiency of the waterjet propulsion pump system under the design flow rate conditions, respectively.

\section{Results and discussion}

\subsection{Hydraulic performance evaluation index of the waterjet propulsion system}

The thrust of the waterjet propulsion system is obtained by means of the calculated reaction force of the water flow ejected from the propulsion pump. Three methods are commonly used in predicting and measuring the thrust of the waterjet propulsion system [1, $19,28]$. These methods are theoretical analysis, experimental measurement and numerical calculation method, i.e. the use of the CFD method. In this study, the thrust of the waterjet propulsion system is calculated by using the momentum flux method and the CFD technology. The thrust is equivalent to the momentum difference between Sections 1A and 7 . Section $1 \mathrm{~A}$ is the imaginary inlet capture area with a semi-elliptical shape located at $1 \mathrm{D}$ ahead of the inlet tangency. Section 7 is the outlet section of the nozzle. Given the influence of the boundary, the thrust of the waterjet propulsion system is defined as follows:

$$
\begin{aligned}
& F=\Delta M=M_{7}-M_{1 A}=\rho Q\left(v_{\text {out }}-v_{\text {in }}\right), \\
& v_{\text {in }}=\alpha^{\prime} v_{s}, \\
& Q=A v_{\text {out }},
\end{aligned}
$$

where $A$ is the outlet area of the nozzle $\left(\mathrm{m}^{2}\right), v_{\text {in }}$ is the mass averaged ingested velocity at Section $1 \mathrm{~A}(\mathrm{~m} / \mathrm{s}), v_{\text {out }}$ is the axial velocity at Section $7(\mathrm{~m} / \mathrm{s})$, and $\alpha^{\prime}$ is the coefficient of the effect of the boundary layer with a value of 0.95 following the reference documentation [19].

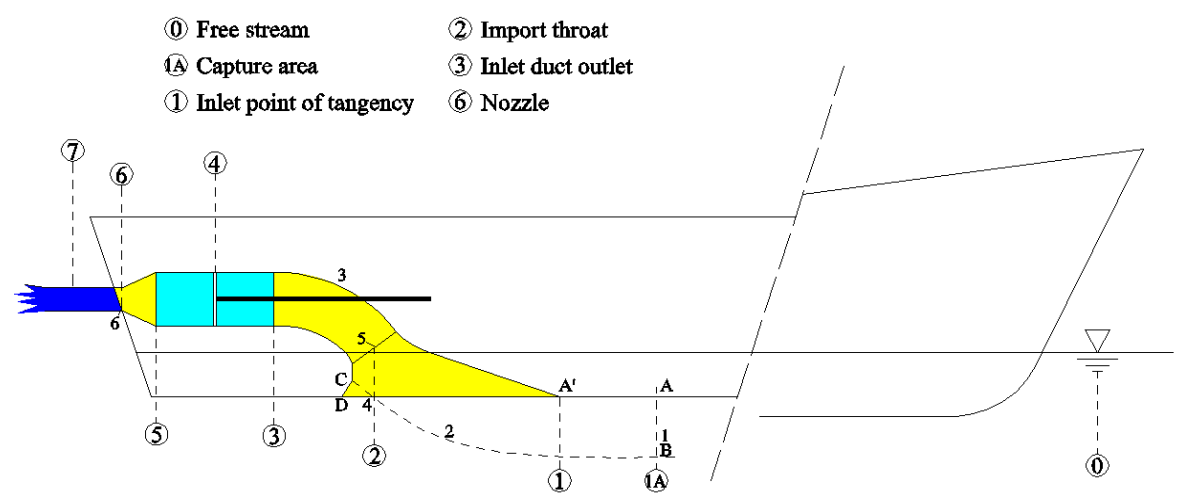

Fig. 10 24th ITTC definitions of standard locations of the waterjet propulsion system 
The efficiency of the waterjet propulsion system $\eta_{c}$ denotes the ratio of the output power of the system to the propulsion pump. Given the pipeline loss coefficient, the following formulas are used to calculate $\eta_{c}$ :

$$
\begin{aligned}
& \eta_{c}=\frac{2\left(k-\alpha^{\prime}\right)}{k^{\prime 2}-\beta+K_{1}}, \\
& \beta=\alpha^{\prime 2}, \\
& k^{\prime}=\frac{v_{\text {out }}}{v_{s}},
\end{aligned}
$$

where $K_{1}$ is the pipeline loss coefficient in the range of $0.40-0.50$. In this study, $k^{\prime}$ is equivalent to $0.45, k^{\prime}$ is the ratio of $v_{\text {out }}$ to $v_{\mathrm{s}}$, and $\beta$ is the coefficient of the effect of the boundary layer.

The energy and cavitation performances of the waterjet propulsion pump are significantly affected by the flow pattern of the impeller. Attention should be paid to the flow pattern of the impeller to improve the efficiency of the waterjet propulsion pump system. A sketch of the setting angle of the impeller blades is shown in Figure 11. $\beta_{0}$ represents the design angle. The parallelogram rule is used to describe the inlet velocity of the impeller blade, as shown in Figure 12. $v_{0}$ denotes the design value of the fluid absolute velocity, $w_{0}$ denotes the design value of the corresponding velocity, and $u$ denotes the subsequent velocity rating. When the velocity distribution in the impeller inlet section is not uniform, the absolute velocity of a particle in this section is less than (or greater than) $v_{0}$. Then, it becomes similar to $v_{1}$ (or $v_{2}$ ), as shown in Figure 12(a). The flow angle $\beta_{1}$ (or $\beta_{2}$ ) must be less than or greater than $\beta_{0}$. Because of the deviation between the flow angle and the design angle, in the process of impeller rotation, the flow will impact the pressure surface or the suction surface of the blade, resulting in an increased hydraulic loss in the impeller. This is also the reason for the occurrence of flow separation, vortices and cavitation on the blade surface. When the velocity of a particle in the impeller inlet section is not perpendicular to that section, it changes the shape of the parallelogram of the inlet velocity and the flow angle, resulting in the occurrence of the bad flow patterns near the impeller inlet, as shown in Figure 12(b).

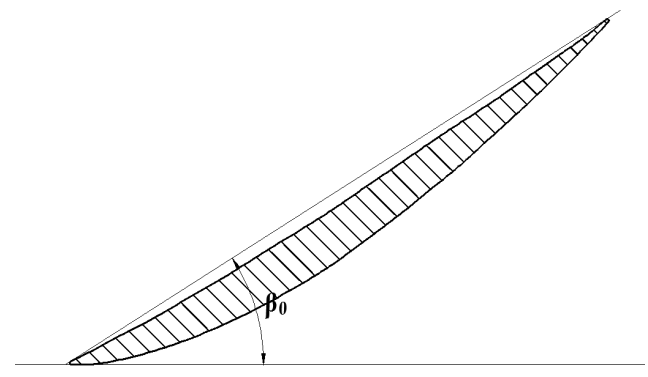

Fig. 11 Sketch of the setting angle of impeller blades

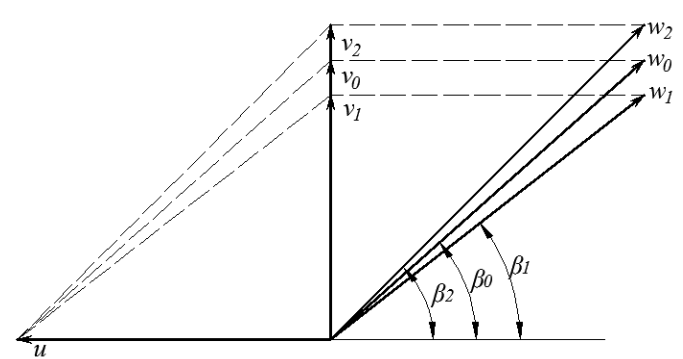

(a)

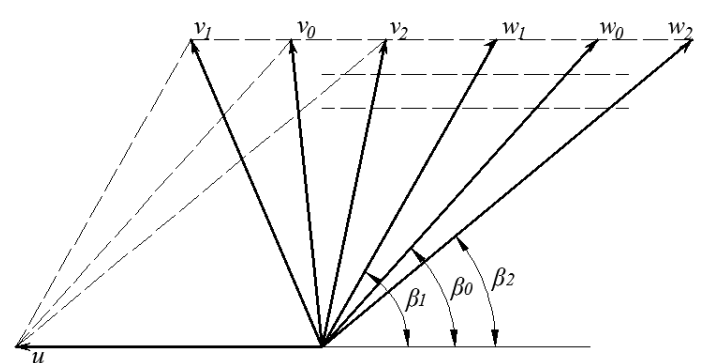

(b)

Fig. 12 Parallelogram rule of velocity at impeller inlet 
The uniformity of the velocity distribution at the impeller inlet section is represented by the axial velocity distribution coefficient $V_{u}$. The axial velocity distribution is best when its coefficient is closer to $100 \%$. The following formula is used to calculate $V_{u}$ :

$$
V_{u}=\left[1-\frac{1}{\overline{v_{a}}} \sqrt{\frac{\sum\left(v_{a i}-\overline{v_{a}}\right)^{2}}{m}}\right] \times 100 \%,
$$

where $v_{a i}$ is the axial velocity of each element of the calculated section $(\mathrm{m} / \mathrm{s}), \overline{v_{a}}$ is the averaged axial velocity of the calculated section $(\mathrm{m} / \mathrm{s})$, and $m$ is the number of cells of the calculated section.

The weighted velocity average swirl angle $\bar{\theta}$ is used to measure the inflow conditions of the impeller. The flow angle perpendicular to the impeller inlet section is better when $\bar{\theta}$ is closer to $90^{\circ}$. The following formula is used to calculate $\bar{\theta}$ :

$$
\bar{\theta}=\frac{\sum_{i=1}^{n}\left[v_{a i}\left(90-\arctan \frac{v_{t i}}{v_{a i}}\right)\right]}{\sum_{i=1}^{n} v_{a i}},
$$

where $v_{t i}$ is the tangential velocity of each element of the calculated section $(\mathrm{m} / \mathrm{s})$.

\subsection{Flow parameters}

The influence of the flow parameters is explored to obtain key parameters of the hydraulic optimization of the inlet duct. The best operation conditions of the waterjet propulsion system are also determined. Ship speed is an important flow parameter of the waterjet propulsion system, and rotational speed is an important flow parameter of the propulsion pump. The propulsion pump exhibits a poor flow pattern under the designed rotational speed $n_{d}$. Under the premise that the ship speed is maintained, the optimal flow conditions can be obtained by adjusting the rotational speed $n$ to increase the flow rate.

The total pressure contour of the propulsion pump inlet under different ship speed conditions is shown in Figure 13. As the ship speed increases, the maximum total pressure distribution area of the propulsion pump inlet also increases gradually. When the ship speed exceeds $12 \mathrm{~m} / \mathrm{s}$, the variation of the maximum total pressure distribution area of the propulsion pump inlet is extremely small, given a gradual increase in the flow rate ejected from the nozzle with an increase in the ship speed and the rotational speed. The total pressure on the left- and right-hand sides of the pump shaft is symmetrically distributed. Thus, the upper part of the pump shaft is a low-pressure zone, whereas the lower part of the pump shaft is a high-pressure zone.

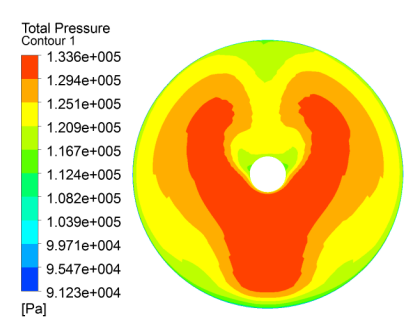

$$
\text { (a) } \begin{gathered}
v_{s}=8 \mathrm{~m} / \mathrm{s}, \\
n / n_{d}=2.29
\end{gathered}
$$
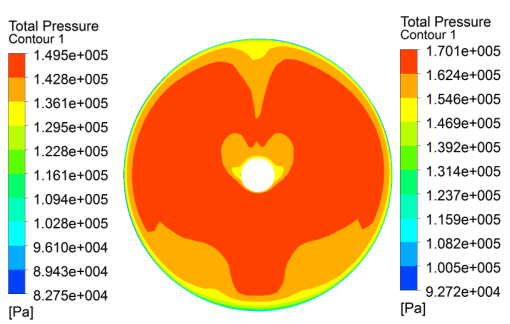
(b) $v_{s}=10 \mathrm{~m} / \mathrm{s}$,
$n / n_{d}=2.71$
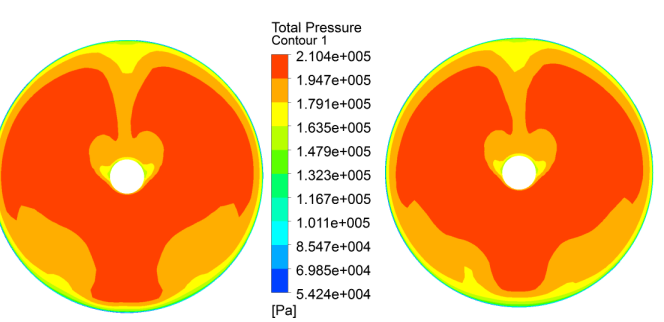

(d) $v_{s}=15 \mathrm{~m} / \mathrm{s}$, $n / n_{d}=4.14$

Fig. 13 Distribution of total pressure contour of the propulsion pump inlet under different ship speed conditions 
The axial velocity distribution coefficient and the weighted velocity average swirl angle of the propulsion pump inlet under different ship speed conditions are shown in Figure 14. The velocity distribution uniformity and the weighted velocity average swirl angle of the propulsion pump inlet are slightly changed. Although the ship speed changes under the optimal flow conditions, the velocity distribution coefficient and the weighted velocity average swirl angle of the propulsion pump inlet are satisfactory, and the velocity distribution coefficient has reached more than $75 \%$. Therefore, under the optimal flow conditions, the change of ship speed has little influence on the hydraulic performance of the propulsion pump inlet.

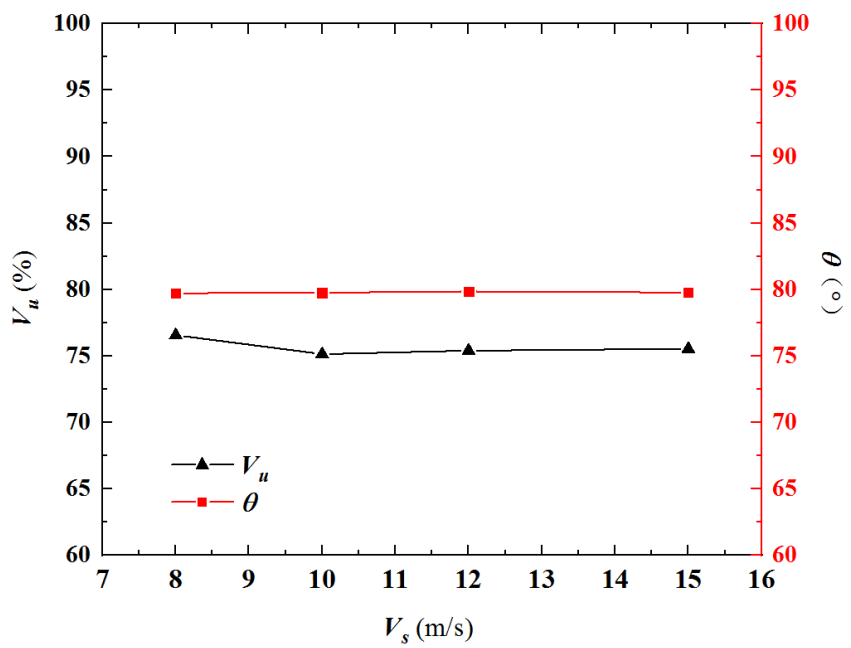

Fig. 14 Axial velocity distribution coefficient and weighted velocity average swirl angle under different ship speed conditions

The internal flow pattern of the waterjet propulsion pump system is uniform under the optimal flow conditions, and no bad flow patterns, such as vortex and flow separation, are observed, as shown in Figure 15. The maximum and minimum velocities inside the waterjet propulsion pump system are increased with an increase in the ship speed and the rotational speed. Thus, the flow pattern of the waterjet propulsion pump system is only slightly affected by the change in the ship speed and the rotational speed.
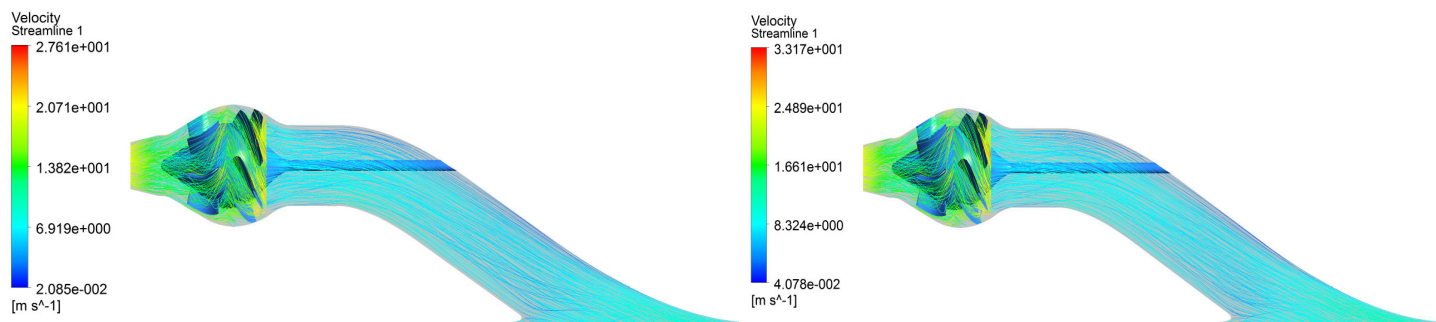

(a) $v_{s}=8 \mathrm{~m} / \mathrm{s}, n / n_{d}=2.29$

(b) $v_{s}=10 \mathrm{~m} / \mathrm{s}, n / n_{d}=2.71$
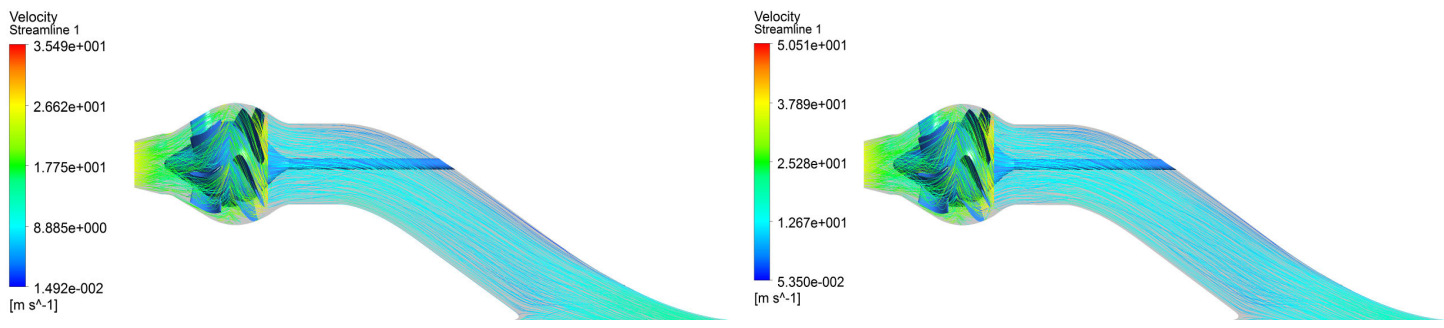

(c) $v_{s}=12 \mathrm{~m} / \mathrm{s}, n / n_{d}=2.86$

(d) $v_{s}=15 \mathrm{~m} / \mathrm{s}, n / n_{d}=4.14$

Fig. 15 Streamlines in the waterjet propulsion pump system under different ship speed conditions 
The system efficiency and thrust under different ship speed conditions are shown in Figure 16. As the ship speed increases, first the system efficiency increases and then it decreases, and the thrust increases continually. When the ship speed reaches approximately $10 \mathrm{~m} / \mathrm{s}$, the efficiency of the waterjet propulsion system obtains a maximum value. Hydraulic performance evaluation indices, such as internal flow patterns, thrust and system efficiency, are considered comprehensively. When the ship speed is $10 \mathrm{~m} / \mathrm{s}$, the rotational speed ratio $n / n_{d}$ is 2.71 , and the overall performance of the waterjet propulsion pump system is optimal. The investigation of the key parameters for the hydraulic optimization of the inlet duct considering the whole waterjet propulsion pump system is conducted under the following conditions: the ship speed is equivalent to $10 \mathrm{~m} / \mathrm{s}$, and the rotational speed is equivalent to $2.71 n_{d}$.

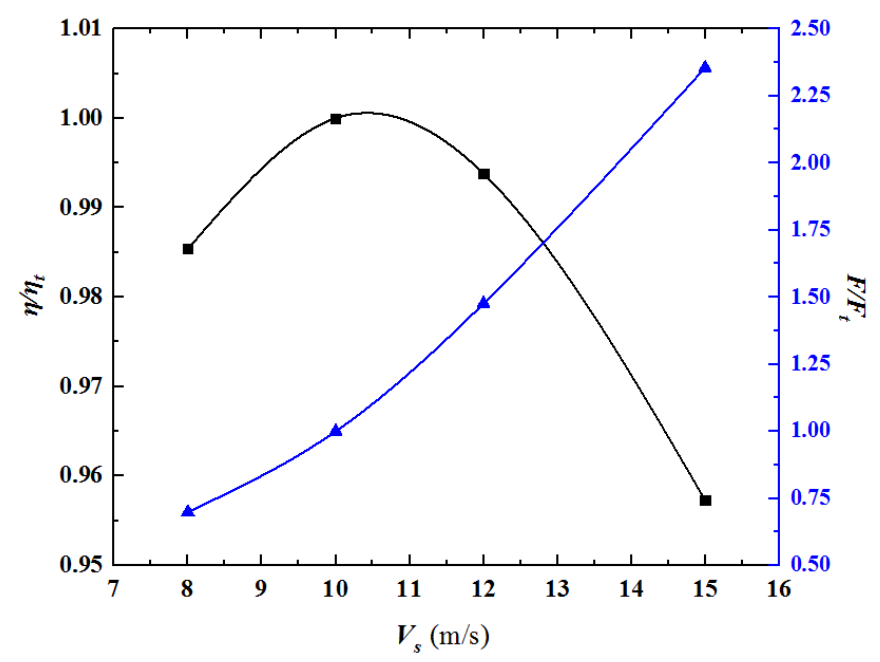

Fig. 16 System efficiency and thrust under different ship speed conditions

\subsection{Geometric parameters}

Length $L$ and dip angle $\alpha$ are the key geometric parameters of the inlet duct. By maintaining the inlet duct outlet diameter and the lip structure, the geometric parameters of length $L$ and dip angle $\alpha$ are analysed using the single factor analysis. The hydraulic performance of the waterjet propulsion pump system is obtained using different geometric parameters. The geometric parameter optimization schemes are shown in Table 2.

Table 2 Geometric parameters of the inlet duct

\begin{tabular}{|c|c|c|c|c|c|c|}
\hline \multirow[b]{2}{*}{ Case } & \multicolumn{3}{|c|}{ Geometric parameter } & \multirow{2}{*}{$\begin{array}{c}\text { Ship } \\
\text { speed } \\
v_{s}(\mathrm{~m} / \mathrm{s})\end{array}$} & \multirow[b]{2}{*}{$\begin{array}{c}\text { Rotational } \\
\text { speed } \\
n / n_{d}\end{array}$} & \multirow[b]{2}{*}{ Note } \\
\hline & $\begin{array}{c}\text { Length } \\
\quad L\end{array}$ & $\begin{array}{c}\text { Dip } \\
\text { angle } \\
\alpha\end{array}$ & $\begin{array}{l}\text { Lip } \\
\text { Structure }\end{array}$ & & & \\
\hline 1 & $5.95 \mathrm{D}$ & $35^{\circ}$ & $4^{\circ}$ & 10 & 2.71 & \\
\hline 2 & $5.73 \mathrm{D}$ & $35^{\circ}$ & $4^{\circ}$ & 10 & 2.71 & \\
\hline 3 & $5.51 \mathrm{D}$ & $35^{\circ}$ & $4^{\circ}$ & 10 & 2.71 & \\
\hline 4 & $5.58 \mathrm{D}$ & $33^{\circ}$ & $4^{\circ}$ & 10 & 2.71 & \\
\hline 5 & $5.76 \mathrm{D}$ & $30^{\circ}$ & $4^{\circ}$ & 10 & 2.71 & $L$ \\
\hline 6 & $6.08 \mathrm{D}$ & $27^{\circ}$ & $4^{\circ}$ & 10 & 2.71 & \\
\hline 7 & $6.13 \mathrm{D}$ & $25^{\circ}$ & $4^{\circ}$ & 10 & 2.71 & \\
\hline
\end{tabular}




\subsubsection{Length $L$}

Sketches of various inlet ducts with different lengths $L$ are depicted in Figure 17. Three cases of inlet ducts with different lengths are observed under the conditions of maintaining the dip angle and the lip of the inlet duct. The influence of length $L$ of the inlet duct on the hydraulic performance of the waterjet propulsion pump system is analysed.

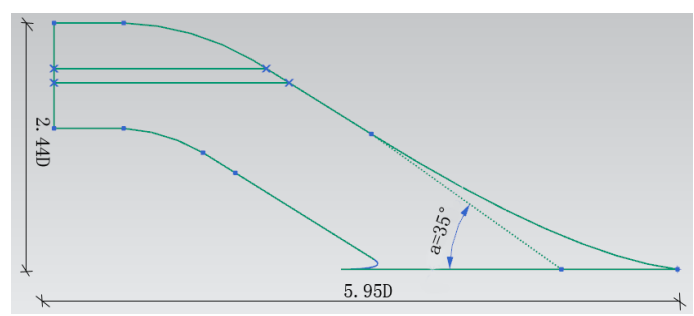

(a) Case 1

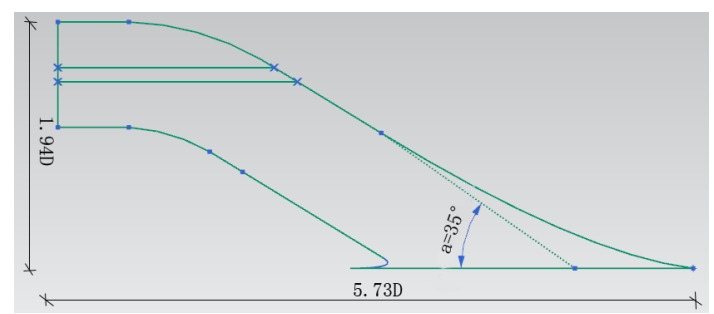

(b) Case 2

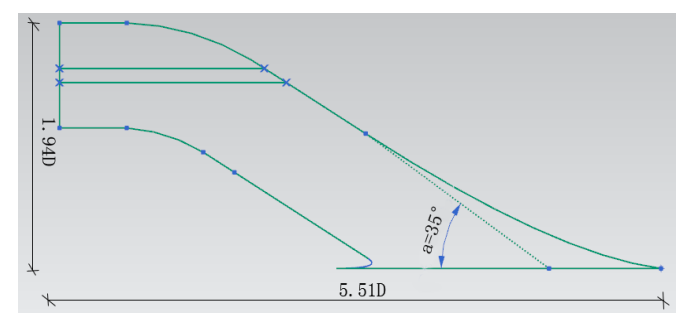

(c) Case 3

Fig. 17 Sketches of different cases involving inlet ducts with different lengths $L$

Streamlines of different cases in the waterjet propulsion pump system are shown in Figure 18. The results show that the internal flow pattern of each case is uniform, and no bad flow pattern is observed. Although the dip angle of the inlet duct is maintained while its length is changed, the internal flow pattern of the waterjet propulsion pump system remains unaffected. Thus, the length of the inlet duct is not a key geometric parameter affecting its internal flow pattern under certain dip angles.
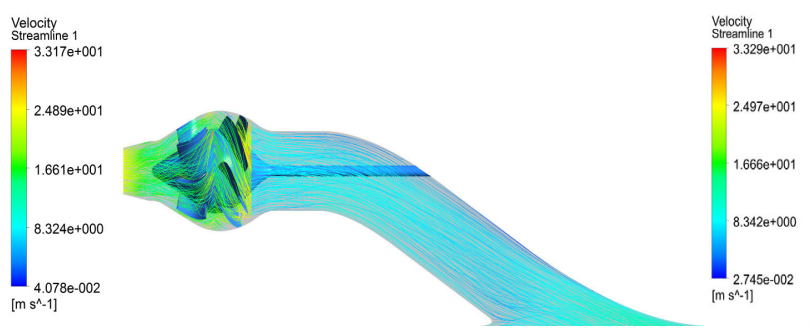

(a) Case 1

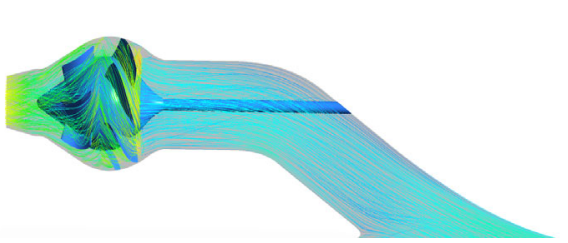

(b) Case 2
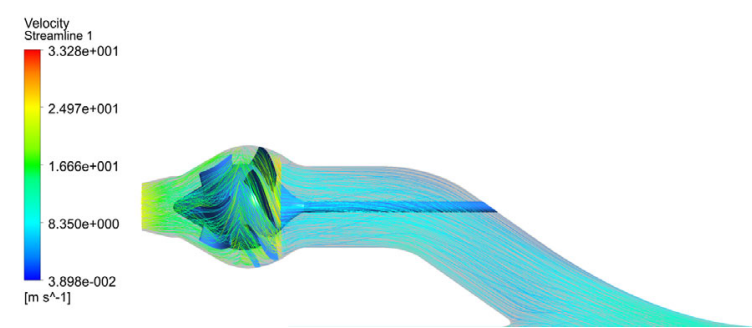

(c) Case 3

Fig. 18 Streamlines of different cases in the waterjet propulsion pump system

The hydraulic performance evaluation index of the waterjet propulsion pump system with different lengths $L$ is shown in Table 3 . The results show that only the length of the inlet duct is changed, and the variation of the velocity uniformity distribution of the propulsion 
pump inlet section in each case is small. As the length of the inlet duct becomes shorter, the thrust and the system efficiency of the waterjet propulsion pump system are slightly reduced. To sum up, by changing the length of the inlet duct, the internal flow pattern of the waterjet propulsion pump system becomes uniform, and the thrust and system efficiency of the waterjet propulsion pump system are reduced. Thus, length $L$ is not a key geometric parameter affecting the hydraulic performance of the waterjet propulsion pump system.

Table 3 Hydraulic performance evaluation index

\begin{tabular}{ccccc}
\hline Case & $V_{u}(\%)$ & $\bar{\theta}\left({ }^{\circ}\right)$ & $F / F_{d}$ & $\eta_{c} / \eta_{c d}$ \\
\hline Case 1 & 75.1 & 79.8 & 1.00 & 1.00 \\
Case 2 & 74.0 & 79.6 & 0.96 & 0.99 \\
Case 3 & 74.8 & 79.6 & 0.96 & 0.99 \\
\hline
\end{tabular}

\subsubsection{Dip angle $\alpha$}

Five cases of inlet ducts are investigated to analyse the influence of dip angle $\alpha$ on the hydraulic performance of the waterjet propulsion pump system. The dip angle of the inlet duct is between $25^{\circ}$ and $35^{\circ}$, as shown in Figure 19.

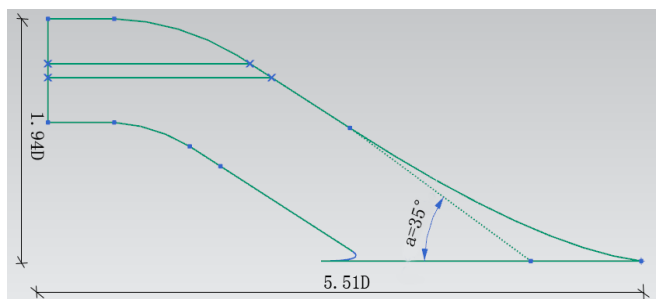

(a) Case 3

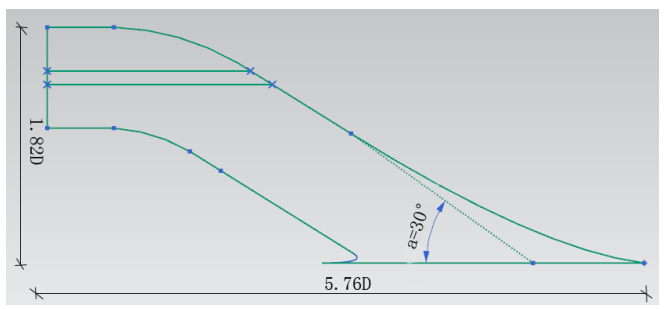

(c) Case 5

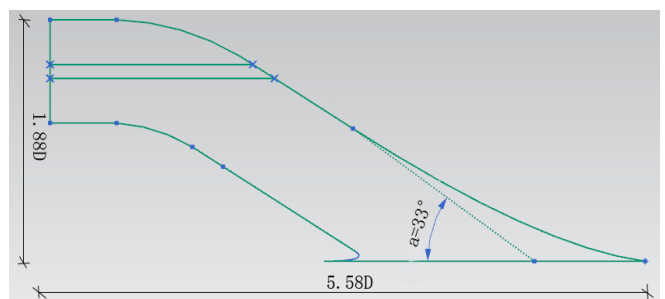

(b) Case 4

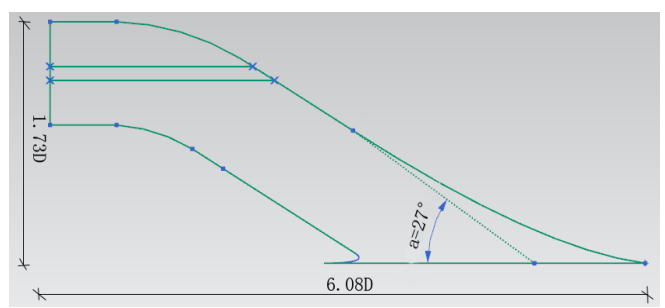

(d) Case 6

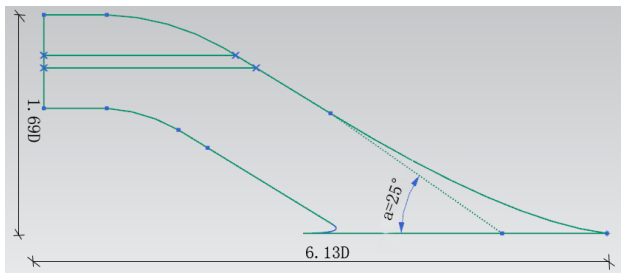

(e) Case 7

Fig. 19 Sketches of different cases involving inlet ducts with different dip angles $\alpha$

Streamlines of different cases in the waterjet propulsion pump system are presented in Figure 20. As the dip angle decreases, bad flow patterns, such as backflow and vortex, occur in the waterjet propulsion pump system at the dip angle of $25^{\circ}$. This condition indicates that the dip angle is a key geometric parameter affecting the internal flow pattern of the waterjet propulsion pump system. As the dip angle of the inlet duct decreases, its height decreases. This condition causes a little vertical distance between the pump shaft and the inlet of the inlet duct. This distance between the two parts is not conducive to the improvement of the flow state in the inlet duct. 

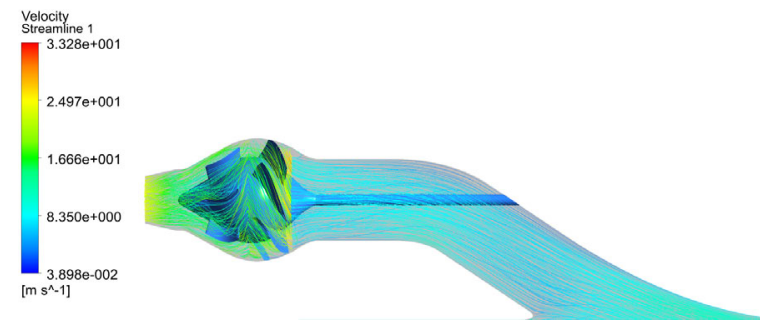

(a) Case 3

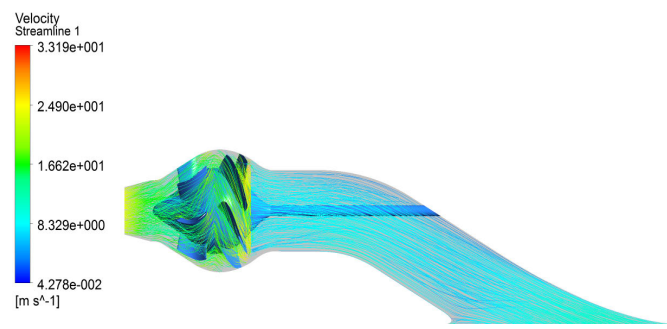

(c) Case 5

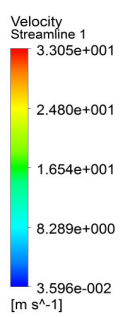

m m s-11
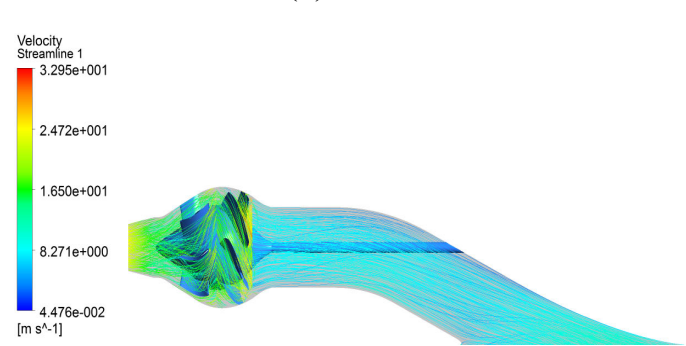

(d) Case 6

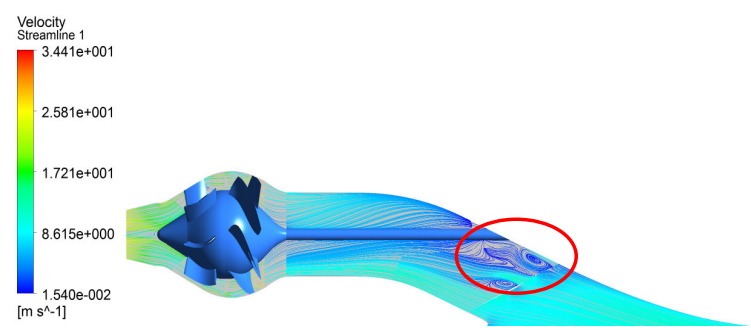

(e) Case 7

Fig. 20 Streamlines of different cases in the waterjet propulsion pump system

The hydraulic performance evaluation index of the waterjet propulsion pump system with different dip angles $\alpha$ is shown in Table 4 . The hydraulic performance evaluation indices of Case 7 are smaller than those of other cases. The velocity uniformity $(2.7 \%)$ and the system efficiency (3\%) of Case 6 are lower than those of Case 4 . The thrust changes of the five cases are small, indicating that the change in the dip angle hardly affects the thrust. To sum up, with a decrease in the dip angle, bad flow patterns, such as backflow and vortex, occur in the waterjet propulsion pump system at the dip angle of $25^{\circ}$. Moreover, the pump system exhibits the lowest efficiency, indicating that the dip angle is a key geometric parameter affecting the hydraulic performance of the waterjet propulsion pump system. The comprehensive hydraulic performance of the waterjet propulsion pump system is satisfactory with the following geometric parameters: an inlet duct length $L$ of approximately $6 \mathrm{D}$, a dip angle of $30^{\circ}-35^{\circ}$, and a sharp lip corner structure.

Table 4 Hydraulic performance evaluation index

\begin{tabular}{ccccc}
\hline Case & $V_{u}(\%)$ & $\bar{\theta}\left({ }^{\circ}\right)$ & $F / F_{d}$ & $\eta_{c} / \eta_{c d}$ \\
\hline Case 3 & 74.8 & 79.6 & 0.96 & 0.99 \\
Case 4 & 75.8 & 80.0 & 0.96 & 0.99 \\
Case 5 & 74.7 & 79.8 & 0.96 & 0.99 \\
Case 6 & 73.1 & 80.0 & 0.97 & 0.96 \\
Case 7 & 68.4 & 77.9 & 0.96 & 0.94 \\
\hline
\end{tabular}

\section{Conclusion}

On the basis of a whole waterjet propulsion pump system, key parameters for the hydraulic optimization of the inlet duct were investigated in this study from two aspects: flow and geometric parameters. The accuracy of the numerical simulation results was checked by 
combining the numerical simulation with experimental verification. By conducting a grid size sensitivity analysis and comparing different turbulence models, a suitable grid size and turbulence model were determined. The numerical simulation results were extremely similar to the experimental results under the design flow rate conditions. Thus, the numerical results were reliable. By calculating and analysing the hydraulic performance of the waterjet propulsion pump system in different cases, the following results were obtained:

(1) Under optimal flow conditions, the internal flow pattern of the waterjet propulsion pump system was good. With an increase in the ship speed and the rotational speed, the efficiency of the waterjet propulsion pump system would increase first and then decrease, whereas the thrust would increase all the time. When the ship speed was $10 \mathrm{~m} / \mathrm{s}$, and the rotational speed was $2.71 n_{d}$, the system efficiency would reach the highest point. When the ship speed was $12 \mathrm{~m} / \mathrm{s}$, a wide range of cavitation was observed inside the inlet duct. Thus, under the optimal flow conditions, the ship speed affected the efficiency of the waterjet propulsion system but had little influence on the flow pattern of the inlet duct. Finally, the operating conditions of $10 \mathrm{~m} / \mathrm{s}$ ship speed and $2.71 n_{d}$ rotational speed were considered the best hydraulic optimization conditions for the waterjet propulsion pump system.

(2) With a decrease in the length $L$ of the inlet duct, the internal flow pattern of the inlet duct would exhibit no obvious change. However, the thrust and the system efficiency of the waterjet propulsion system would decline. Bad flow patterns, such as backflow and vortex, would occur in the waterjet propulsion pump system with a dip angle of $25^{\circ}$, and the system efficiency would reach the lowest level. When the angle of inclination was more than $30^{\circ}$ and less than $35^{\circ}$, the comprehensive hydraulic performance of the waterjet propulsion system was satisfactory. By exploring the effects of length $L$ and dip angle $\alpha$ of the inlet duct, the latter was considered to be the key parameter affecting the comprehensive performance of the waterjet propulsion system. To sum up, the hydraulic performance of the waterjet propulsion system was satisfactory under the following conditions in terms of the propulsion pump assembly: an inlet duct length of approximately $6 \mathrm{D}$, a dip angle of $30^{\circ}-35^{\circ}$, and a sharp lip angle structure.

\section{Acknowledgments}

This study is supported by the National Natural Science Foundation of China (Grant No.51779214), Peak plan six talents in Jiangsu Province (Grant No.2015-JXQC-007), Jiangsu Province 333 high-level talents training project, Jiangsu Planned Projects for Postdoctoral Research Funds (Grant No. 1701189B), Project Funded by the Priority Academic Program Development of Jiangsu Higher Education Institutions (PAPD), Key Project of Water Resources Technology in Jiangsu Province (Grant No. 2019014), and Yancheng New Water Source and Water Diversion Project.

\section{Nomenclature}

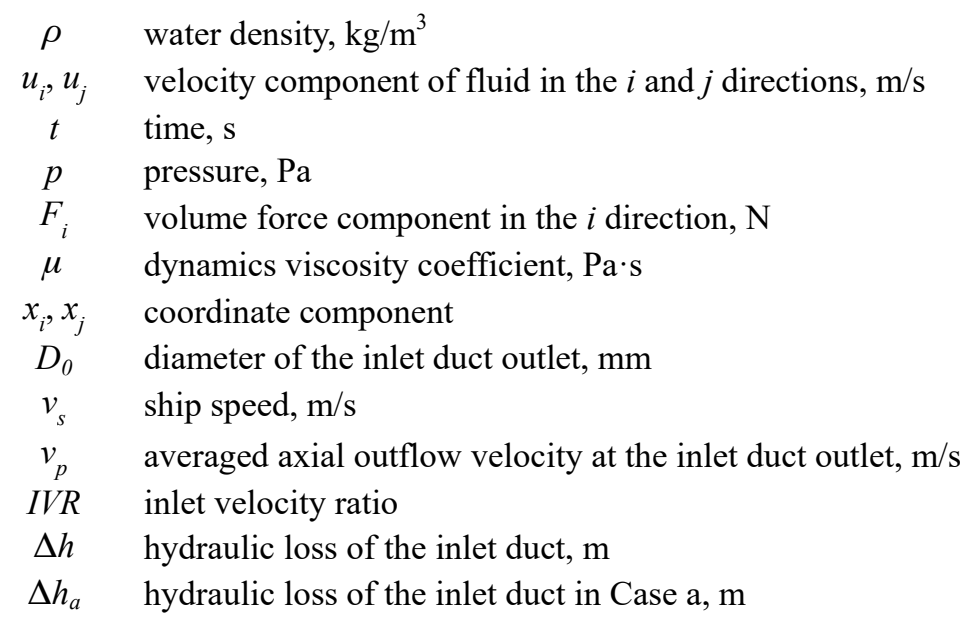


Investigation of Key Parameters for

Hydraulic Optimization of an Inlet Duct Based on a

Whole Waterjet Propulsion Pump System
W. Jiao, L. Cheng, D. Zhang,

B. Zhang, Y. Su

$H_{t d} \quad$ test value of head under design flow rate condition, m

$\eta_{t d} \quad$ test value of efficiency under design flow rate condition, $\%$

$p_{1-1} \quad$ average total pressure of section $1-1, \mathrm{~Pa}$

$p_{2-2} \quad$ average total pressure of section $2-2, \mathrm{~Pa}$

$g$ gravitational acceleration, $\mathrm{m} / \mathrm{s}^{2}$

$T$ torque of blades, $\mathrm{N} \cdot \mathrm{m}$

$Q \quad$ flow rate, $\mathrm{m}^{3} / \mathrm{s}$

$P \quad$ shaft power, $\mathrm{kW}$

$n \quad$ rotational speed of the impeller, $\mathrm{r} / \mathrm{min}$

$Q_{d} \quad$ design flow rate, $\mathrm{m}^{3} / \mathrm{s}$

$H_{d} \quad$ head under design flow rate condition, $\mathrm{m}$

$\eta_{d} \quad$ efficiency under design flow rate condition, $\%$

A outlet area of the nozzle, $\mathrm{m}^{2}$

$v_{\text {out }}$ axial velocity at Section $7, \mathrm{~m} / \mathrm{s}$

$v_{\text {in }} \quad$ mass averaged ingested velocity at Section $1 \mathrm{~A}, \mathrm{~m} / \mathrm{s}$

$\alpha^{\prime} \quad$ doefficient of the effect of the boundary layer

$K_{l} \quad$ pipeline loss coefficient

$k$ ratio of $v_{\text {out }}$ to $v_{s}$

$B \quad$ coefficient of the effect of the boundary layer

$V_{u} \quad$ axial velocity distribution coefficient, $\%$

$v_{a i} \quad$ axial velocity of each element of the calculated section, $\mathrm{m} / \mathrm{s}$

$\overline{v_{a}} \quad$ averaged axial velocity of the calculated section, $\mathrm{m} / \mathrm{s}$

$M \quad$ number of cells of the calculated section

$\bar{\theta} \quad$ weighted velocity average swirl angle, ${ }^{\circ}$

$v_{t i} \quad$ tangential velocity of each element of the calculated section, $\mathrm{m} / \mathrm{s}$

$n_{d} \quad$ designed rotational speed of the impeller, $\mathrm{r} / \mathrm{min}$

$L \quad$ length of the inlet duct, $\mathrm{m}$

$A$ dip angle, ${ }^{\circ}$

$H \quad$ height of the inlet duct, $\mathrm{m}$

$F \quad$ thrust of the waterjet propulsion system, N

$\eta_{c} \quad$ efficiency of the waterjet propulsion system, $\%$

$F_{t} \quad$ thrust of the waterjet propulsion system with $v_{s}=10 \mathrm{~m} / \mathrm{s}, \mathrm{N}$

$\eta_{t} \quad$ efficiency of the waterjet propulsion system with $v_{s}=10 \mathrm{~m} / \mathrm{s}, \%$

$F_{d} \quad$ thrust of the waterjet propulsion system in Case 1, N

$\eta_{c d}$ efficiency of the waterjet propulsion system in Case 1, \%

\section{REFERENCES}

[1] N.W.H.Bulten. Numerical Analysis of a Waterjet Propulsion System.2006.

[2] Takai T, Kandasamy M, Stern F. Verification and validation study of URANS simulations for an axial waterjet propelled large high-speed ship. Journal of Marine Science \& Technology, 2011, 16(4):434-447. https://doi.org/10.1007/s00773-011-0138-x

[3] Lavis D R, Forstell B G, Purnell J G. Compact waterjets for high-speed ships. Ships and Offshore Structures, 2007, 2(2):11. https://doi.org/10.1080/17445300701430101

[4] Jiao, W; Zhang, D; Wang, C; et al. Unsteady numerical calculation of oblique submerged jet. Energies, 2020, 13(18), 4728. https://doi.org/10.3390/en13184728

[5] ALLISON J L. Marine waterjet propulsion, Proceeding of SNAME. 1993, 101:275-335.

[6] Wang, H; Long, B; Yang, Y; et al. Modelling the influence of inlet angle change on the performance of submersible well pumps. International Journal of Simulation Modelling, 2020, 19(1): 100-111. https://doi.org/10.2507/ijsimm19-1-506

[7] Wang, H, Long, B, Wang, C, et al. Effects of the Impeller Blade with a Slot Structure on the Centrifugal Pump Performance. Energies, 2020, 13, 1628. https://doi.org/10.3390/en13071628

[8] Wu X F, Tian X, Tang M G, et al. Multi-Parameter Optimization and Analysis on Performance of a Mixed Flow Pump. Journal of Applied Fluid Mechanics, 2020, 13 (1):199-209.

https://doi.org/10.29252/jafm.13.01.30077 
[9] Suh J W, Yang H, Kim Y I, et al. Multi-objective optimization of a high efficiency and suction performance for mixed-flow pump impeller. Engineering Applications of Computational Fluid Mechanics, 2019, 13(1):744-762. https://doi.org/10.1080/19942060.2019.1643408

[10] Shi, L, Zhang, W, Jiao, H, et al. Numerical simulation and experimental study on the comparison of the hydraulic characteristics of an axial-flow pump and a full tubular pump. Renewable Energy, 2020, 153:1455-1464. https://doi.org/10.1016/j.renene.2020.02.082

[11] Shi, L, Zhu, J, Tang, F, et al. Multi-Disciplinary Optimization Design of Axial-Flow Pump Impellers Based on the Approximation Model. Energies, 2020, 13(4), 779. https://doi.org/10.3390/en13040779

[12] Gu, Y, Pei, J, Yuan, S, et al. A Pressure Model for Open Rotor-Stator Cavities: An Application to an Adjustable-Speed Centrifugal Pump with Experimental Validation. Journal of Fluids Engineering, 2020, 142(10): 101301. https://doi.org/10.1115/1.4047532

[13] Jiao W X, Cheng L, Xu J, et al. Numerical Analysis of Two-Phase Flow in the Cavitation Process of a Waterjet Propulsion Pump System. Processes, 2019, 7(10): 690. https://doi.org/10.3390/pr7100690

[14] Huang R F, Luo X W, Ji B, et al. Multi-objective optimization of a mixed-flow pump impeller using modified NSGA-II algorithm. Science China Technological Sciences, 2015, 58(12):2122-2130. https://doi.org/10.1007/s11431-015-5865-5

[15] Wang X E, Zhang Z S, Jin S B. Optimization Design of Water Jet Propulsion Equipped on High Speed. Journal of Wuhan University of Technology, 2017, 41(01):64-69.

[16] Cao P Y, Wang Y, Li G D, et al. Optimum condition of water. jet propulsion [J]. Journal of Drainage and Irrigation Machinery Engineering, 2015, 33(2):145-151.

[17] Park W G, Yun H S, Chun H H, et al. Numerical flow simulation of flush type intake duct of waterjet. Ocean Engineering, 2005, 32(17/18):2107-2120. https://doi.org/10.1016/j.oceaneng.2005.03.001

[18] Jung K H, Kim K C, Yoon S Y, et al. Investigation of turbulent flows in a waterjet intake duct using stereoscopic PIV measurements. Journal of Marine Science \& Technology, 2006, 11(4):270-278. https://doi.org/10.1007/s00773-006-0236-3

[19] Chin P C. Water jet propulsion of the vessel, Beijing: National Defence Industrial Press, 1986.

[20] Verbeek R. Recent development in waterjet design. Proceeding of International Conference on Waterjet Propulsion II. Amsterdam: RINA, 1998.

[21] Cao P Y, Wang Y, Kang C, et al. Investigation of the role of non-uniform suction flow in the performance of water-jet pump. Ocean Engineering, 2017, 140: 258-269. https://doi.org/10.1016/j.oceaneng.2017.05.034

[22] Wu F, Dong X S, Wu Y B, et al. Hydraulic Properties of the Flow in a Gradual Shrinking and Sudden Enlarging Channel. Journal of North China University of Water Resources and Electric Power (Natural Science Edition), 2017(02):65-71.

[23] Hu L M, Chai D W. Influence of Inlet Conduit Blockage of Pumping Station on Its Hydraulic Performance. Water Resources and Power, 2018, 36(08):158-161.

[24] He X K, Zhang H L, Wang Z L, et al. Influence of Critical Wall Roughness on the Performance of Double-Channel Sewage Pump. Energies, 2020, 13(2):464. https://doi.org/10.3390/en13020464

[25] Liu C J, Wang Y S, Zhang Z H, et al. Research on effect of different flow control volume on waterjet performance prediction. Journal of Ship Mechanics, 2010, 10 (14), 1117-1121.

[26] ANSYS ICEM CFD, Version 14.5; ANSYS Inc, USA, 2012.

[27] Wang, H, Qian, Z, Zhang, D, et al. Numerical study of the normal impinging water jet at different impinging height, based on Wray-Agarwal turbulence model. Energies 2020, 13, 1744. https://doi.org/10.3390/en13071744

[28] Liu C J, Wang Y S, Zhang Z H, et al. Research on computational methods of waterjet thrust using CFD. Chinese Journal of Computational Mechanics, 2008, 25(6):927-931.

Submitted: $\quad$ 24.5.2019

Accepted: $\quad 04.11 .2020$

\author{
Mr. Weixuan Jiao \\ Prof. Li Cheng* \\ Mr. Di Zhang \\ Mr. Bowen Zhang \\ Mr. Yeping Su \\ College of Hydraulic Science and \\ Engineering, Yangzhou University, \\ Yangzhou, Jiangsu, P.R. China \\ *Corresponding author, \\ chengli@yzu.edu.cn
}

